\title{
Geographic health inequalities in Madrid City: exploring spatial patterns of respiratory disease mortality
}

\author{
María-Eugenia Prieto-Flores ${ }^{*}$, Diana Gómez-Barroso², \\ Rosa Cañada Torrecilla ${ }^{3}$, Antonio Moreno Jiménez ${ }^{3}$ \\ ${ }^{1}$ National Council of Scientific and Technical Research (CONICET), Institute of \\ Geography, National University of La Pampa, Argentina \\ ${ }^{2}$ National Center of Epidemiology, Carlos III Institute of Health, CIBERESP, Spain \\ ${ }^{3}$ Department of Geography, Autonomous University of Madrid, Spain
}

The unequal geographic distribution of health determinants could denote situations of environmental injustice. This work aims to identify spatial patterns of respiratory disease mortality and their association with the education level and the atmospheric pollution in Madrid. To this purpose, we applied spatial analysis through statistical techniques and Geographic Information Systems at the census tract level. The analysis showed a slight but significantly higher risk of mortality in areas with more unfavourable socioeconomic and environmental conditions. This work has the potential to inform public policy and research on links among social, environmental and health inequalities in Madrid City.

Key Words: geographic health inequalities, respiratory mortality, air pollution, sociodemographic groups, Geographic Information Systems.

Article Info: Received: April 3, 2020; Revised: April 24, 2021; Accepted: May 15, 2021; Online: May 31, 2021.

\section{"Corresponding author}

Address: Institute of Geography, National University of La Pampa. Coronel Gil 353, 6300, Santa Rosa, La Pampa, Argentina.

Phone: +54-2954-451664| Email: meprieto@conicet.gov.ar

(C)2021 Human Geographies; The authors

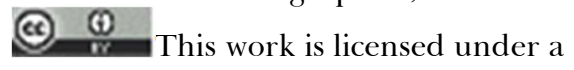

Creative Commons Attribution 4.0 International License. DOI:10.5719/hgeo.2021.151.1 


\section{Introduction}

The study of health inequalities has an important tradition in geography, contributing to the knowledge of the role of space and place in the variations in populations' health (Curtis \& Jones, 1998; Gatrell, 2002; Santana et al., 2015). Depending on the theoretical and methodological approaches applied, we can identify a range of health geographies, from those dedicated to the spatial analysis of disease, the effects of environmental degradation, and access to health services, to those that include the experiences of health and illness, therapeutic landscapes and the study of social injustice (Gatrell, 2002; Kearns, 1993; Rosenberg, 1998; Rosenberg \& Wilson, 2005).

The spatial analysis of disease, in particular, helps to determine whether its distribution is random or if there is some pattern, in which case, helps to understand what environmental or social factors might cause it. Within this context, understanding sociospatial inequalities in health continues to be of great importance to geographers, epidemiologists, public health researchers and policymakers, among others (Pearce et al., 2010), and the vital role of geospatial data, technology and methods for promoting healthy communities has been highlighted by experts such as those of the Centers for Disease Control and Prevention (CDC) (Elmore et al., 2010).

The study of health inequalities spatial patterns has been approached from different geographic scales, showing increased inequalities among countries, regions and neighbourhoods in the same city, as Pearce et al. point out (2015). In their work, these authors underline three areas of research that have contributed to a better understanding of geographical health inequalities. Firstly, they look at the importance of local space: the place where we live, work, study and play influence our health. The second area focuses on the study of environmental justice, which highlights the disproportionate burden of environmental problems that are borne by the most disadvantaged population groups (Walker, 2012); and thirdly, the authors examine population mobility and migration, including questions such as selective migration and the effect that moving from one place to another has on the health of those who migrate.

Among the various studies of the health inequalities are those related to chronic diseases, which currently represent the leading cause of death and disability in most countries worldwide, especially cardiovascular and respiratory disease, cancer and diabetes (WHO, 2005). Some of the factors that influence chronic diseases the most are socioeconomic (level of education, income and occupation), lifestyles, characteristics of the neighbourhood, poverty, pollution and public policy (Cockerham et al., 2017). An unequal sociospatial distribution of these health determinants, which have a greater effect on the most vulnerable groups of the population, could denote situations of environmental injustice. In this direction, we can highlight the negative effect of atmospheric pollution on cardiovascular and respiratory health (Jerrett et al., 2005; WHO, 2013) and its greater impact on disadvantaged groups as they are more often exposed to pollution, but they are also more susceptible to its effects on health (WHO, 2010). 
Accordingly, urban areas involve health threats with exposures and vulnerabilities inequitably distributed (Schikowski et al., 2008).

Within this context, the aim of this work is to identify spatial patterns of respiratory disease mortality and establish their connection with socioeconomic characteristics and air pollution in the city of Madrid and detect possible sociospatial inequalities or environmental injustices. This hypothetical relationship will be studied using education level as a socioeconomic indicator and air particulate matter - an important component of air quality. Through this empirical study, we seek to contribute to the research on environmental injustice from a geographical perspective and to add information to the studies developed in Spain, paying particular attention to sociospatial imbalances (Bosque Sendra et al., 2001-2002; Moreno Jiménez, 2007, 2013; Moreno Jiménez et al., 2016; PrietoFlores et al., 2017).

\section{Methodology}

The study area corresponds to the city of Madrid, the capital of Spain, which has an area of $604.3 \mathrm{~km}^{2}$ with a population of 3,223,334 (Spanish Statistical Office, 2019) and a density of 53.3 inhabitants/ha. Census tracts were used for the analyses, as they are the smallest territorial units used for the publication of statistical information and have between 1,000 and 2,500 inhabitants. In order to limit the study area to places where there is a habitual and significant presence of residents, the populated urban area was used (Figure 1), which was defined employing aerial images (National Aerial Orthophotography Program of the National Geographic Institute of Spain) and land use cartography (Corine Land Cover, 2006), with the support of Geographic Information Systems (GIS), as described in our previous work (Moreno Jiménez, 2016). This urban populated area has $270,90 \mathrm{~km}^{2}$ and a density of about 120,82 inhabitants/ha.

The data consist of three types of variables: standardized mortality ratio (SMR) calculated for respiratory diseases mortality, sociodemographic characteristics of the population and air particulate matter $\left(\mathrm{PM}_{10}\right)$, by census tract of Madrid populated urban area. The mortality data were obtained from the Statistical Office of the Regional Government of Madrid, based on sex, age and census tract of residence of the deceased person in 2010. The basic causes of death that were analysed correspond to those in Chapter X of the ICD-10 International Statistical Classification of Diseases: deaths resulting from diseases of the respiratory system. In addition to this data, in order to calculate the SMR, the authors used the population of the Municipal Register of Inhabitants from the same year, published by the Spanish Statistical Office and stratified by sex and four age groups $(0-14,15-64,65-79$ and 80 or more years old) at the census tract level for the urban populated area of Madrid.

As a socio-economic criterion, the authors used the percentage of adults aged 30 to 59 with a low level of educational attainment (failed to complete primary school) from each census tract. 


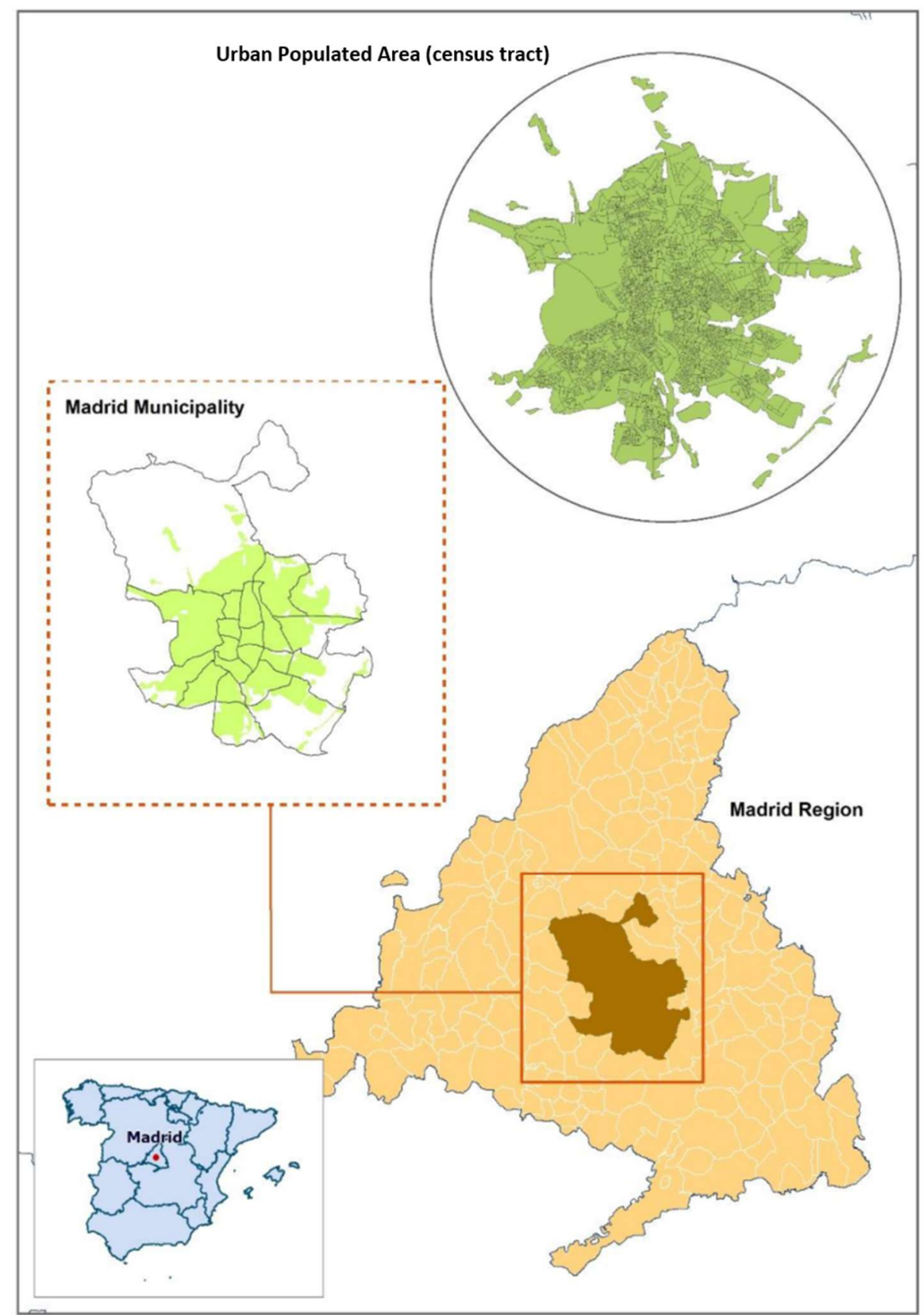

Figure 1. Urban populated area of Madrid City

The information was imputed exclusively for the urban populated area and integrated into a GIS program (ArcGIS) in both vector and raster format for analytical and cartographic purposes (Vidal Domínguez \& Palacios García, 2012). Pollution was measured using the air particulate matter less than or equal to 10 micrometres in diameter $\left(\mathrm{PM}_{10}\right)$. Measurements of the concentration of these fine 
particles are made by recording their mass in one cubic metre of air, using the units' micrograms per cubic metre $\left(\mu \mathrm{g} / \mathrm{m}^{3}\right)$. The air particulate material is primarily produced by mechanical processes such as construction works and road dust re-suspension, but they also include smaller particulates that come primarily from combustion sources.

In this regard, it must be stressed that the finest particles $(<2.5)$ typically represent 50 to $75 \%$ of $\mathrm{PM}_{10}$ (Querol et al., 2008). These particles impact public health, significantly affecting the respiratory and cardiovascular systems, as it has been repeatedly demonstrated in cities around the world (WHO, 2013). The maximum annual average of $\mathrm{PM}_{10}$ recommended by WHO is $20 \mu \mathrm{g} / \mathrm{m}^{3}$, although the level set by Spanish and the European Union law is $40 \mu \mathrm{g} / \mathrm{m}^{3}$. For the purposes of this research, the WHO threshold was adopted, which is more demanding in terms of protecting human health.

The $\mathrm{PM}_{10}$ data were provided by the City Council and the Regional Government of Madrid and come from 24 monitoring stations of Madrid City and 8 stations of neighbouring municipalities. The information was collected in 2010. A spatial interpolation using kriging was applied to generate a map representing the annual mean concentrations of $\mathrm{PM}_{10}$. The techniques were applied using Geostatistical Analyst (ArcGIS) and were detailed in previous work (Cañada Torrecilla et al., 2014).

First, the age-adjusted SMR for respiratory diseases mortality in the study area was calculated by estimating the expected cases for each geographical unit (census tract in the urban populated area), taking the overall rate of the city as a reference. Once the expected cases were obtained, the SMR for each census tract was calculated, taking as numerator the observed cases and as denominator the expected cases for each unit. The SMR measures the relative risk of a census tract with respect to the region of reference.

The next step was carrying out a cluster analysis using the Getis-Ord Local G statistic, which shows the concentration of high and low values in the study area. The results of the analysis are interpreted, taking the null hypothesis as reference. The null hypothesis for high/low clustering establishes that there is no spatial clustering of entities. If the P-value is statistically significant, the null hypothesis is rejected, and the $\mathrm{z}$-value is then calculated based on this (standard deviations). If the $\mathrm{z}$-score value is positive, the observed General $\mathrm{G}$ index is greater than the expected General $G$ index, indicating that high values for the attribute are clustered in the study area. On the contrary, if the z-score value is negative, the observed General G index is smaller than the expected index, indicating that low values are clustered in the study area.

The authors studied the association of intraurban distribution of the SMR with socioeconomic status and pollution, using a Poisson spatial regression model, with observed cases of respiratory mortality as the dependent variable, expected cases as offset, and two random effects terms that took the following into account: a) census tract contiguity (spatial term), and b) census tract heterogeneity. Socioeconomic status and air pollution were introduced into the model as continuous explanatory variables. 


\section{Results}

A total number of 3,266 deaths attributable to respiratory diseases were recorded in 2010 in Madrid, distributed across various census tracts. Figure 2 represents the distribution of the SMR of respiratory mortality in the city. An SMR higher than 1 indicates the number of deaths is greater than expected in this area. The mean and standard deviation were $1.17 \pm 1.62$, with a range of 0 to 32.39 . The orange and red colours on the map correspond to a higher relative risk than expected, showing a heterogeneous distribution. In order to correctly interpret the map, it is important to mention that the area of the census tracts varies greatly, although the size of the population does not, which is between 1,000 and 2,500 residents. Some spatial clusters were identified when using the Local G (Figure 3). A significant positive value of $G$ (in red) indicates a cluster of high values of SMR with reference to the expected General G index. These clusters are located especially in the southern half of the city. A significant negative value of $G$ represents a group of low values with respect to the expected General G index.

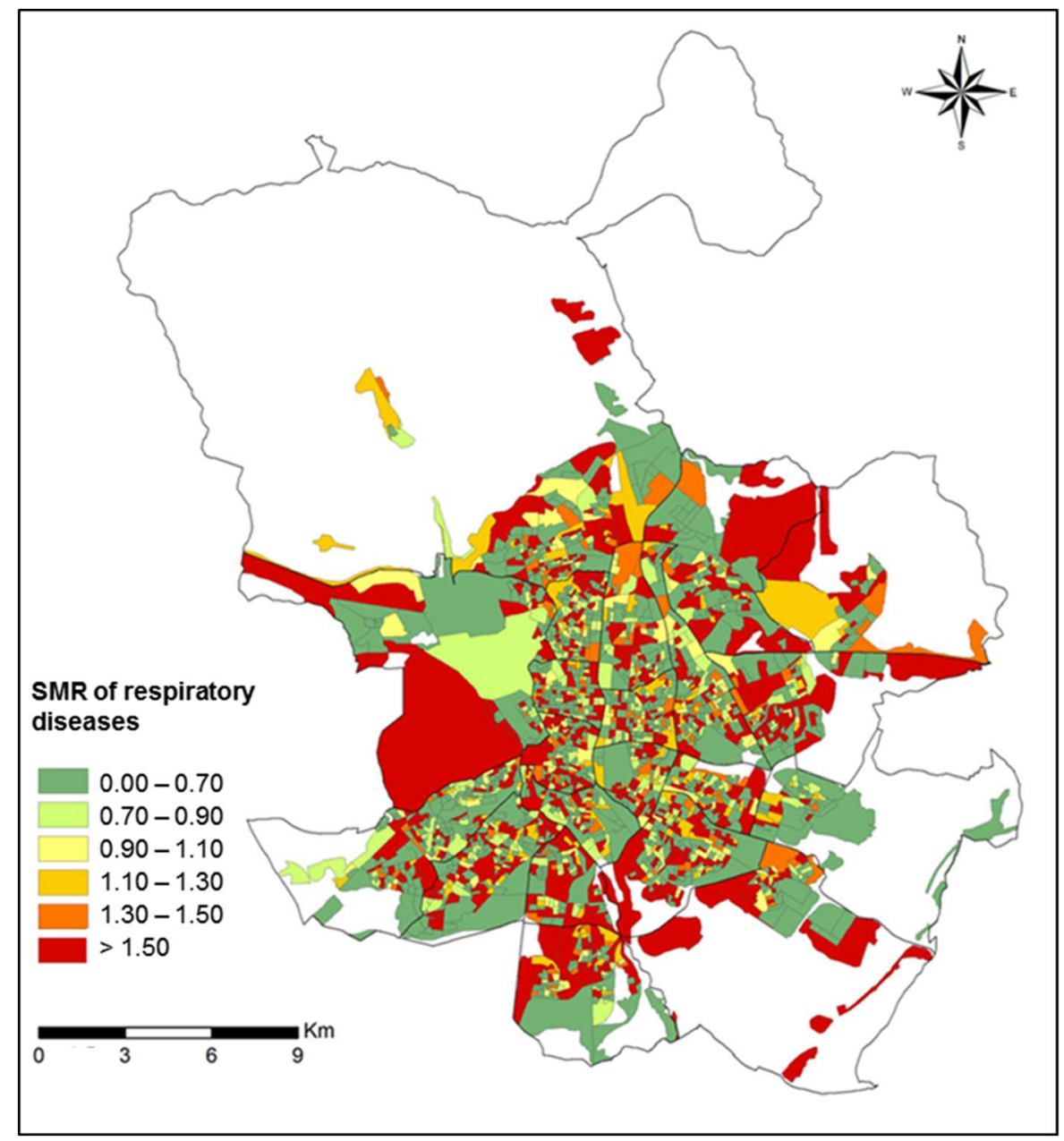

Figure 2. Spatial distribution of SMR for respiratory diseases in Madrid 2010 


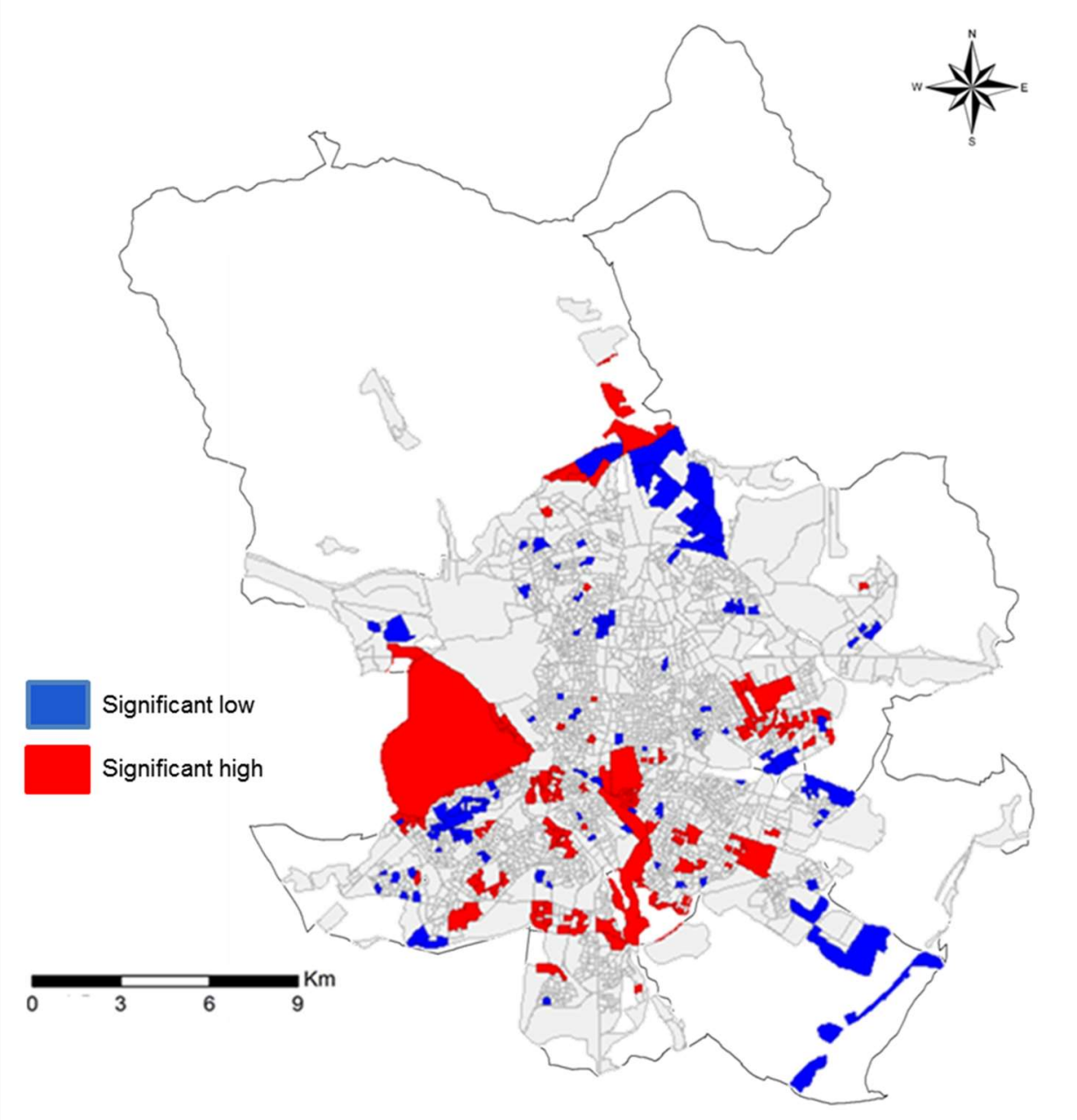

Figure 3. Spatial clusters of SMR for respiratory diseases mortality in Madrid 2010: Local $\mathrm{G}$ cluster map

A more disadvantaged socioeconomic situation was measured using educational attainment per census tract, as explained previously. The percentage of adults aged 30 to 59 who did not complete primary school showed a mean and standard deviation of $11.58 \pm 8.38$, with a range of $0.54-61.57$.

In order to represent the distribution of the city's population density and the level of educational attainment (Figure 4), raster layers were prepared, assigning to each pixel of $50 \mathrm{~m}$ resolution the value resulting from the ratio between the individuals of each census tract and the number of pixels in that tract. When comparing to the general distribution of the population, there is a higher concentration of people with a low level of educational attainment in the southern half of the city, as well as in the south of the city centre district.

The particulate air pollution $\left(\mathrm{PM}_{10}\right)$ had a mean and standard deviation of $22.88 \pm 1.75$, with a range of 17.54-26.81. The spatial distribution across the city of Madrid (Figure 5) highlights a pattern of higher levels (above $25 \mu \mathrm{g} / \mathrm{m}^{3}$ ) in the 
centre, coinciding with the highest traffic intensity, as well as in areas in the southern and south-eastern periphery. This may be related to the particles that originate from dry soils with insufficient vegetation cover abundant in neighbouring areas. The lowest levels of $\mathrm{PM}_{10}$, below the maximum recommended WHO limit $\left(20 \mu \mathrm{g} / \mathrm{m}^{3}\right)$, are in the west and north, representing just only $22.7 \%$ of Madrid's urban populated area.

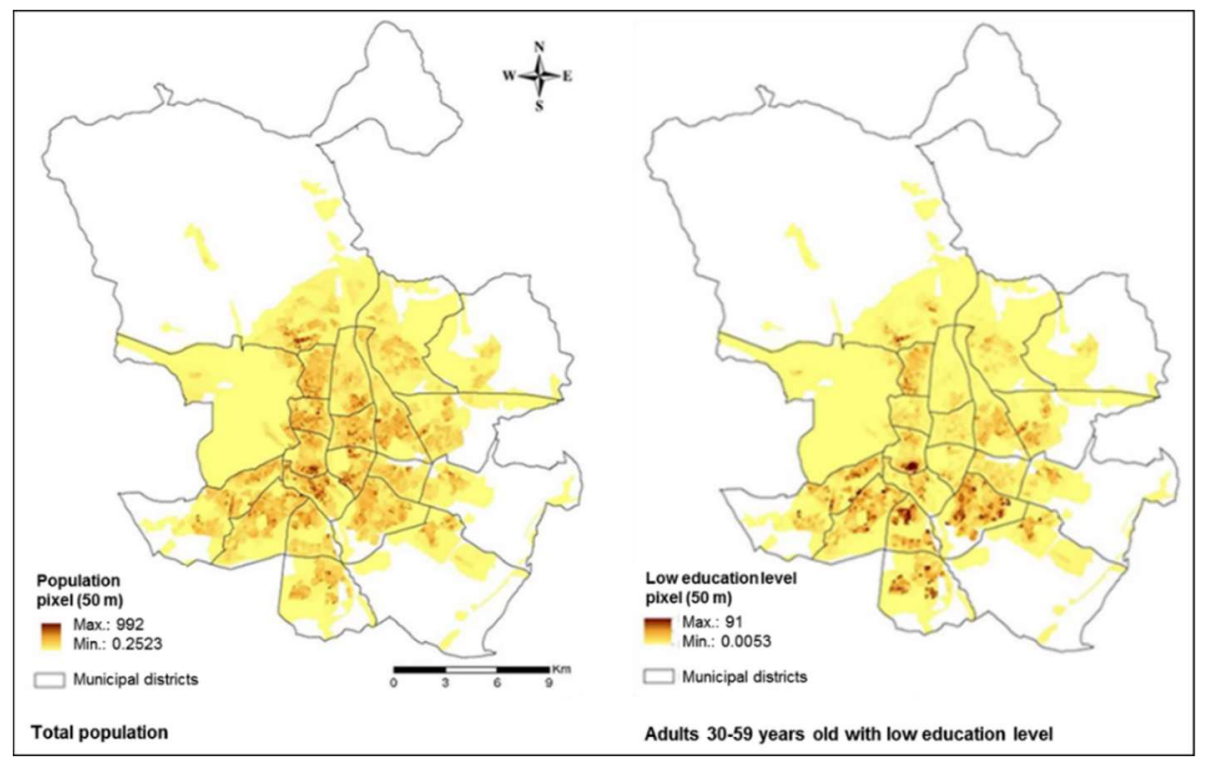

Figure 4. Population density and adults with a low level of educational attainment in Madrid 2010.

Source: Reprinted from Prieto-Flores et al., 2017

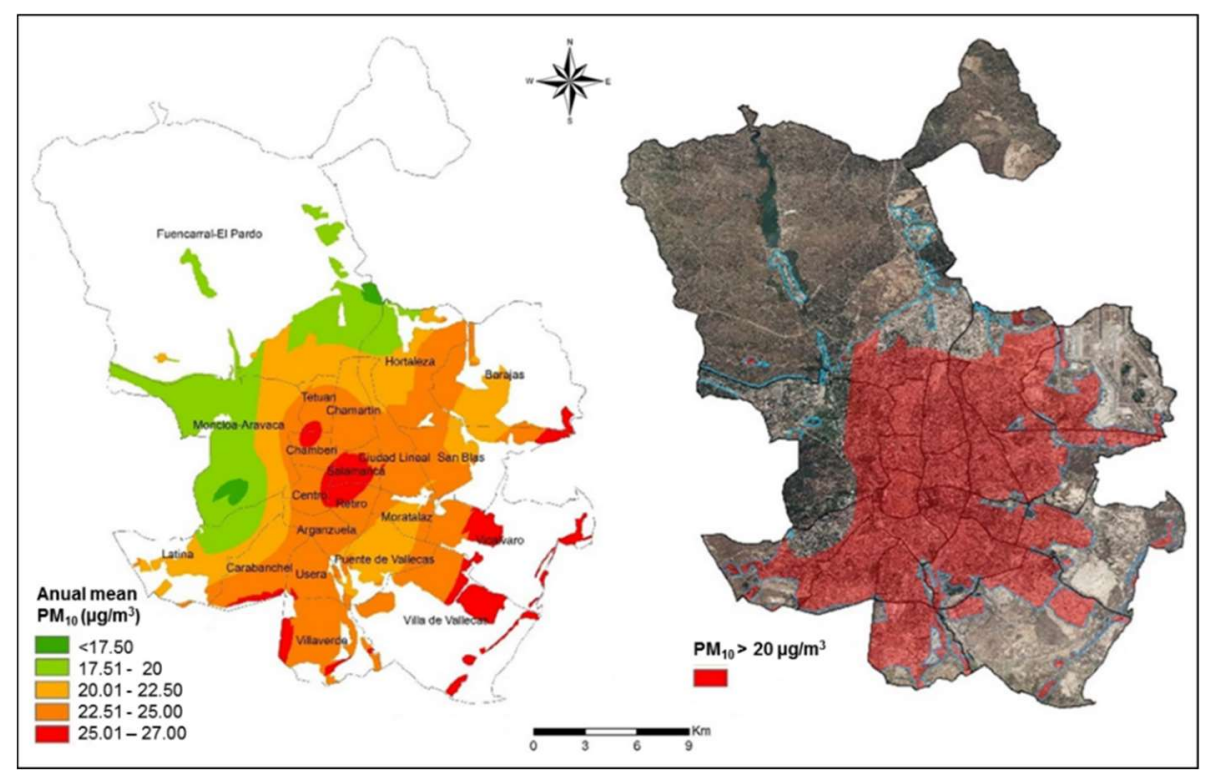

Figure 5. Spatial distribution of air pollution $\mathrm{PM}_{10}$ in Madrid 2010.

Source: Reprinted from Prieto-Flores et al., 2017 
The study variables were integrated into a regression model (Poisson spatial model) to analyse the spatial relationship of the SMR for respiratory diseases with the socioeconomic level and the air pollution in Madrid. Both explanatory variables are significant in the model, according to the relative risk (RR) and the $95 \%$ confidence interval (CI) between the 0.025 quantile and 0.975 quantile. The results show a slight increase in the RR of mortality in areas with higher annual mean levels of PM10 (RR: 1.025; CI: 1.002-1.050), and in areas with a lower level of educational attainment (RR: 1.011; CI: 1,006-1.016) represented by the proportion of adults aged 30 to 59 that did not complete primary school. This helps corroborate the hypothesis of the study about social and environmental inequalities in health in the intraurban space of Madrid city.

\section{Discussion}

In this study, the authors explored the geographical distribution of the SMR for respiratory diseases, socioeconomic status represented by education level and the amount of air pollution per $\mathrm{PM}_{10}$ in Madrid intraurban area. Secondly, it was investigated whether or not the spatial pattern of the SMR was related to the socioeconomic level and pollution in order to detect possible sociospatial and environmental inequalities. To undertake this research, statistical and GIS techniques in Madrid urban populated area by census tract were applied, integrating information from several different databases.

The maps allowed the visualization of spatial patterns of the selected health, socioeconomic and environmental variables. The highest concentration of disadvantageous circumstances across these three criteria tended to be found in the centre and south of the city. These spatial patterns show similarities with those observed in the Mortality Atlas of Spanish Cities (Borrell et al., 2009), specifically the SMR distribution (considering all causes of death together) as well as Madrid socioeconomic distribution. Other research that has taken place in Madrid has shown a convergence, in the south of the city, of low-income areas and a greater number of days with a high concentration of $\mathrm{PM}_{10}$ in the atmosphere, suggesting a situation of environmental inequality (Cañada Torrecilla et al., 2011).

WHO (2010) indicates that air pollution contributes to increasing social inequalities in population health through a higher level of exposure to pollutants and a greater susceptibility for the most vulnerable population groups. Laurent et al. (2007), in their systematic review of the effect of socioeconomic status on the relationship between air pollution and mortality, identified a more significant impact on the most deprived people.

The spatial regression model allowed the analysis in an integrated way of the outcome variable of respiratory diseases mortality, based on socioeconomic level and air pollution and, at the same time, controlling for the spatial dependency. The results showed a slight but significantly higher risk of respiratory mortality in places with low educational attainment and higher concentrations of $\mathrm{PM}_{10}$. 
Accordingly, the results of this article point to the existence of socio-spatial inequalities. An intraurban imbalanced distribution of respiratory mortality depending on the socioeconomic level was observed, in line with the studies undertaken in several Spanish cities (Borrell et al., 2010) and various European cities (Marí-Dell'Olmo et al., 2015), which show a relationship between socioeconomic deprivation and geographical inequality in the mortality from respiratory causes. The results also suggest that the spatial distribution of the SMR in Madrid shows a link to air pollution, increasing the evidence on the impact of exposure to $\mathrm{PM}_{10}$ on deaths resulting from diseases of the respiratory system (Pelucchi et al., 2009). The greater risk of mortality in areas with more unfavourable socioeconomic and environmental conditions suggests the existence of environmental injustices in Madrid.

Some main methodological issues need to be considered to interpret the results. Firstly, data from only one year was used in the analysis, as opposed to having information from a more extended period, which would have allowed to provide a more complete information on respiratory mortality and air pollution in the study area. Secondly, in this research, it is not possible to differentiate between mortality cases for types of respiratory diseases, as they were examined together. Thirdly, while the level of educational attainment is a good socioeconomic indicator, it does not completely represent the socioeconomic situation of the population. However, at a census tract level, other indicators such as the risk of poverty, income and unemployment are not available, as they can be obtained only at a higher aggregated level (by district) in the city of Madrid.

Despite these limitations, the results of this work add new information on geographic inequalities in health, specifically in the urban populated area of Madrid, contributing to advancing the investigation on spatial injustices on a local scale and with the potential to inform public policy. Research on spatial patterns in chronic diseases continues to be necessary in order to identify, understand and help reduce social, environmental and geographic inequalities in health.

\section{Acknowledgements}

This research has been supported by the Spanish Ministry of Economy and Competitiveness project grants CSO2011-26177 and CSO2014-55535-R.

\section{References}

Borrell, C., Marí-Dell'Olmo, M., Serral, G., Martínez-Beneito, M. and Gotsens, M. (2010), "Inequalities in mortality in small areas of eleven Spanish cities (the multicenter MEDEA project)", Health E Place, vol. 16, no. 4, p. 703-711.

Borrell, C., Serral, G., Martínez-Beneito, M.Á., Marí-Dell'Olmo, M., RodríguezSanz, M. and MEDEA grup (2009), Atlas of mortality in Spanish cities (1996-2003), Dit i Fet, Barcelona. 
Bosque Sendra, J., Díaz Castillo, C. and Díaz Muñoz, M. (2001-2002), "De la justicia espacial a la justicia ambiental en la política de localización de instalaciones para la gestión de residuos en la Comunidad de Madrid", Boletín de la Real Sociedad Geográfica, no. 137-138, p. 89-114.

Cañada Torrecilla, M.R., Moreno Jiménez, A. and González Lorenzo, H. (2014), "Modelado de la calidad del aire urbano. Un experimento metodológico con técnicas de interpolación espacial", Boletín de la Asociación de Geógrafos Españoles, no. 65 , p. 317-342.

Cañada Torrecilla, R., Vidal Domínguez, M.J. and Moreno Jiménez, A. (2011), "Interpolación espacial y visualización cartográfica para el análisis de la justicia ambiental: ensayo metodológico sobre la contaminación por partículas atmosféricas en Madrid", GeoFocus, no. 11, p. 118-154.

Cockerham, W.C., Hamby, B.W. and Oates, G.R. (2017), "The Social Determinants of Chronic Disease", American Journal of Preventive Medicine, vol. 52, no. 1S1, p. S5-S12.

Curtis, S. and Jones, I.R. (1998), "Is there a place for geography in the analysis of health inequality? ", Sociology of Health छ Illness, vol. 20, no. 5, p. 645-672.

Elmore, K., Flanagan, B., Jones, N.F. and Heitgerd, J.L. (2010), "Leveraging geospatial data, technology, and methods for improving the health of communities: priorities and strategies from an expert panel convened by the CDC", Journal of Community Health, vol. 35, no. 2, p. 165-171.

Gatrell, A.C. (2002), Geographies of health: an introduction, Blackwell Publishing, Oxford.

Jerrett, M., Burnett, R.T., Ma, R., Pope, C.A., Krewski, D., Newbold, K.B., Thurston, G., Shi, Y., Finkelstein, N., Calle, E.E. and Thun, M.J. (2005), "Spatial Analysis of Air Pollution and Mortality in Los Angeles", Epidemiology, vol. 16, no. 6, p. 727-736.

Kearns, R.A. (1993), "Place and Health: Towards a Reformed Medical Geography", Professional Geographer, no. 45, vol. 2, p. 139-147.

Laurent, O., Bard, D., Filleul, L. and Segala, C. (2007), "Effect of socioeconomic status on the relationship between atmospheric pollution and mortality", Journal of Epidemiology and Community Health, vol. 61, no. 8, p. 665-675.

Marí-Dell'Olmo, M., Gotsens, M., Palència, L., Burström, B., Corman, D., Costa, G., Deboosere, P., Díez, Ė., Domínguez-Berjón, F. and Dzúrová, D. (2015), "Socioeconomic inequalities in cause-specific mortality in 15 European cities", Journal of Epidemiology and Community Health, vol. 69, no. 5, p. 432-441.

Moreno Jiménez, A. (2007), "¿Está equitativamente repartida la contaminación sonora urbana? Una evaluación desde el principio de justicia ambiental en la ciudad de Madrid", Estudios Geográficos, vol. 68, no. 263, p. 595-626.

Moreno Jiménez, A. (2013), "Población y polución atmosférica intraurbana por dióxido de nitrógeno en Madrid: análisis desde la justicia ambiental basado en Sistemas de Información Geográfica", Cuadernos Geográficos, vol. 52, no. 1.

Moreno Jiménez, A., Cañada Torrecilla, R., Vidal Domínguez, M.J., Palacios García, A. and Martínez Suárez, P. (2016), "Assessing environmental justice in Madrid and Barcelona, Spain: A preliminary analysis of population potential exposure to nitrogen dioxide pollution", Geoforum, no. 69, p. 117-131. 
Pearce, J., Mitchell, R. and Shortt, N. (2015), "Place, space, and health inequalities", in K.E. Smith, C. Bambra and S.E. Hill (eds) Health Inequalities: Critical Perspectives, Oxford University Press, Oxford, p. 192-205.

Pearce, J., Richardson, E., Mitchell, R. and Shortt, N. (2010), "Environmental justice and health: the implications of the socio-spatial distribution of multiple environmental deprivation for health inequalities in the United Kingdom", Transactions of the Institute of British Geographers, vol. 35, no. 4, p. 522-539.

Pelucchi, C., Negri, E., Gallus, S., Boffetta, P., Tramacere, I. and La Vecchia, C. (2009), "Long-term particulate matter exposure and mortality: a review of European epidemiological studies", BMC Public Health, vol. 9, no. 453.

Prieto-Flores, M.-E., Moreno Jiménez, A., Gómez-Barroso, D., Cañada Torrecilla, R. and Martínez Suárez, P. (2017), "Contaminación del aire, mortalidad cardiovascular y grupos vulnerables en Madrid: un estudio exploratorio desde la perspectiva de la justicia ambiental", Scripta Nova. Revista Electrónica de Geografía y Ciencias Sociales, vol. 21, no. 559.

Querol, X., Alastuey, A., Moreno, T., Viana, M.M., Castillo, S., Pey, J., Rodríguez, S., Artiñano, B., Salvador, P., Sánchez, M., Garcia Dos Santos, S., Herce Garraleta, M.D., Fernandez-Patier, R., Moreno-Grau, S., Negral, L., Minguillón, M.C., Monfort, E., Sanz, M.J., Palomo-Marín, R., Pinilla-Gil, E., Cuevas, E., de la Rosa, J. and Sánchez de la Campa, A. (2008), "Spatial and temporal variations in airborne particulate matter (PM10 and PM2.5) across Spain 1999-2005", Atmospheric Environment, vol. 42, no. 17, p. 3964-3979.

Rosenberg, M.W. (1998), "Medical or health geography? Populations, peoples and places", International Journal of Population Geography, vol. 4, no. 3, p. 211-226.

Rosenberg, M. W. and Wilson, K. (2005), "Remaking medical geography". Territoris (Monográfico sobre Geografía de la Salud), no. 5, p. 17-32.

Santana, P., Freitas, A., Costa, C. and Vaz, A. (2015), "Evaluating population health: the selection of main dimensions and indicators through a participatory approach", European Journal of Geography, vol. 6, no. 1, p. 51-63.

Schikowski, T., Sugiri, D., Reimann, V., Pesch, B., Ranft, U. and Kramer, U. (2008), "Contribution of smoking and air pollution exposure in urban areas to social differences in respiratory health", BMC Public Health, vol. 8, no. 179.

Spanish Statistical Office (2019), Cifras oficiales de población resultantes de la revisión del padrón municipal a 1 de enero, 06 March 2020, shorturl.at/quLZ3.

Vidal Domínguez, M.J. and Palacios García, A. (2012), "Apuntes metodológicos para el estudio de las desigualdades sociodemográficas intraurbanas", in P. Reques and O. Cos (eds) La población en clave territorial. Procesos, estructuras y perspectivas. XIII Congreso de Población Española, Universidad de Cantabria, Santander, 457-464.

Walker, G. (2012), Environmental justice: concepts, evidence and politics, Routledge, New York.

WHO (2005), Preventing chronic diseases. A vital investment: WHO global report, World Health Organization, Geneva.

WHO (2010), Environment and health risks: a review of the influence and effects of social inequalities, WHO, Regional Office for Europe, Copenhagen.

WHO (2013), Review of evidence on health aspects of air polution-REVIAAP, WHO, Regional Office for Europe, Copenhagen. 